\title{
Differences in the risk of mood disorders in patients with asthma-COPD overlap and in patients with COPD alone: a nationwide population-based retrospective cohort study in Korea
}

\author{
Hye-Rim Kang ${ }^{1}$, Sung-Hyun Hong ${ }^{1}$, So-Young Ha ${ }^{1}$, Tae-Bum Kim² ${ }^{2^{*}}$ and Eui-Kyung Lee ${ }^{1 *}$ (I)
}

\begin{abstract}
Background: Although feelings of anxiety and depression are common in patients with chronic obstructive pulmonary disease (COPD), little is known about the estimates of their incidence in patients with asthma-COPD overlap (ACO), which has been described and acknowledged as a distinct clinical entity. We aimed to estimate the risk of depression and anxiety among patients with $\mathrm{ACO}$ and compare it with the risk among those with COPD alone in the general population.

Methods: We conducted a nationwide population-based retrospective cohort study using the Korean National Sample Cohort database between 1 January, 2002, and 31 December, 2013. Patients who were diagnosed with COPD (International Classification of Diseases, 10th revision [ICD-10] codes J42-J44) at least twice and prescribed COPD medications at least once between 2003 and 2011 were classified into two categories: patients who were diagnosed with asthma (ICD-10 codes J45-J46) more than twice and at least once prescribed asthma medications comprised the ACO group, and the remaining COPD patients comprised the COPD alone group. Patients who had been diagnosed with depression or anxiety within a year before the index date were excluded. We defined the outcome as time to first diagnosis with depression and anxiety. Matched Cox regression models were used to compare the risk of depression and anxiety among patients with ACO and patients with COPD alone after propensity score matching with a 1:1 ratio.
\end{abstract}

Results: After propensity score estimation and matching in a 1:1 ratio, the cohort used in the analysis included 15,644 patients. The risk of depression during the entire study period was higher for patients with ACO than for patients with COPD alone (adjusted hazard ratio, 1.10; 95\% confidence interval, 1.03-1.18; $P$ value $=0.0039$ ), with an elevated risk in patients aged $40-64$ years $(1.21 ; 1.10-1.34 ; 0.0001)$ and in women $(1.18 ; 1.07-1.29 ; 0.0005)$. The risk of anxiety was higher for patients with ACO than for patients with COPD alone (1.06; 1.01-1.12; 0.0272), with a higher risk in patients aged $40-64$ years $(1.08 ; 1.00-1.17 ; 0.0392)$; however, the risk was not significant when stratified by sex.

Conclusions: This population-based study revealed a higher incidence of depression and anxiety in patients with ACO than in patients with COPD alone.

Keywords: Asthma-COPD overlap, Depression, Anxiety, Mood disorder

\footnotetext{
* Correspondence: tbkim@amc.seoul.kr; ekyung@skku.edu

${ }^{2}$ Department of Allergy and Clinical Immunology, Asan Medical Center,

University of Ulsan College of Medicine, Seoul, Korea

'School of Pharmacy, Sungkyunkwan University, 2066, Seobu-ro, Jangan-gu,

Suwon-si, Gyeonggi-do 16419, South Korea
}

(c) The Author(s). 2019 Open Access This article is distributed under the terms of the Creative Commons Attribution 4.0 International License (http://creativecommons.org/licenses/by/4.0/), which permits unrestricted use, distribution, and reproduction in any medium, provided you give appropriate credit to the original author(s) and the source, provide a link to the Creative Commons license, and indicate if changes were made. The Creative Commons Public Domain Dedication waiver (http://creativecommons.org/publicdomain/zero/1.0/) applies to the data made available in this article, unless otherwise stated. 


\section{Background}

Chronic obstructive pulmonary disease (COPD) is a heterogeneous disease that is associated with aging and tobacco consumption; however, other exposures have also been causally related. Comorbidities contribute to the overall severity and economic burden of COPD [1]. Among such comorbidities, anxiety and depression contribute to a substantial burden of COPD-related morbidity, notably by impairing quality of life and reducing adherence to treatment [2]. In addition, recent studies have investigated the relationship between depression and anxiety with asthma, and they have shown that asthma is associated with depression and anxiety [3-5]. To date, most respiratory studies have included either patients with asthma alone (no COPD) or patients with COPD alone (no asthma) [6]. However, patients older than 40 years may present with mixed features of both COPD and asthma, which has been called Asthma-COPD overlap (ACO) [7]. Although previous studies have reported on the clinical features and poor outcomes of ACO [8, 9], there is still a debate over the defining features and disease severity of ACO [10]. Nevertheless, one of the relevance of the ACO is to identify patients with COPD who may have underlying eosinophilic inflammation that responds better to inhaled corticosteroids [9]. ACO can be useful for clinicians in terms of identifying patients with an expected poor outcome through overlapping clinical characteristics of asthma and COPD [10, 11]. Therefore, coexistence of asthma and COPD can serve as a criterion to assume ACO in a patient with COPD.

In 2017, the Global Initiative for Asthma (GINA) and Global Initiative for Chronic Obstructive Lung Disease (GOLD) committees released an updated document on the description of asthma-COPD overlap (ACO), which is characterized by persistent airflow limitation with several features usually associated with asthma and several features usually associated with COPD [7]. Compared with patients with COPD alone, patients with $\mathrm{ACO}$ are often considered to have different clinical manifestations, with more respiratory symptoms (such as dyspnoea and wheezing), worse health-related quality of life, more frequent exacerbations, and more comorbidities [12-14]. A previous cohort study showed a higher risk of depression in the ACO cohort compared to non-ACO cohort (adjusted HR 1.67, 95\% CI 1.48-1.88) [15]. To avoid selection bias, the authors set a propensity score matched non-ACO cohort set as a comparison cohort using sex, age, and comorbidities; however, the difference in the use of ICS and oral steroid between the two cohorts remained significant. In addition, the socioeconomic status or health-care use have not been considered in the process of selecting non-ACO cohort. Therefore, selection bias still cannot be ruled out. In contrast, ACO and COPD share several common characteristics, including persistent airflow limitation and smoking, which comprise a critical diagnostic criterion and a source of these diseases, respectively [7]. Considering that asthma is a heterogeneous disease that includes patients with wide variations in the age of onset, disease severity, pulmonary function, body mass index, presence of atopy, and Th2 eosinophil inflammation [16-18], the COPD alone cohort is likely to serve as a more appropriate comparison group to achieve clinically meaningful results.

In addition, treatment options and responses may differ depending on whether a patient has COPD alone or ACO $[9,19]$; therefore, it is important to determine comorbidities associated specifically with ACO and COPD. Because mood disorder is a common comorbidity in chronic respiratory diseases, including asthma and COPD [20], it is important to identify mood disorders and provide additional treatment to reduce the disease burden. However, unlike the prevalence of other comorbidities, the incidence of depression and anxiety among patients with ACO compared to COPD alone is little known. Therefore, we conducted a population-based retrospective cohort study to estimate the risks of depression and anxiety among patients with $\mathrm{ACO}$ and compared them with the risks among those with COPD alone.

\section{Methods}

\section{Data source}

This study used the National Sample Cohort data from the National Health Insurance Service (NHIS-NSC) of Korea. The NHIS uses a systematic sampling approach to randomly select a representative population of approximately 1 million people between 2002 and 2013, which is $2.2 \%$ of the total population. The sample cohort was compared with the entire population with respect to the average total annual medical expenses, residence distribution, and the mean and standard deviation of health insurance premiums; the differences were negligible during the cohort years [21]. The data gives researchers access to demographic data - including sex, age recorded at 5-year intervals, income level, and date of death - as well as the health care data - including clinical diagnoses, medical procedures, expenditures, and drug prescriptions. Information on prescribed drugs included the generic drug name, prescription date, duration, and route of administration.

\section{Study population}

To investigate the risk of depression and anxiety in patients with ACO and patients with COPD alone, we constructed a COPD cohort using National Sample Cohort data for the period between January 2003 and December 2011. The COPD cohort included patients older than 40 years who had been diagnosed with COPD at least twice 
as a principal or secondary diagnosis coded according to the International Classification of Disease, tenth revision (ICD-10 codes J42, J43, and J44) and with at least 1 prescription for $\geq 1$ of the following COPD medications: inhaled corticosteroids (ICSs), inhaled long-acting $\beta 2$-agonists (LABAs), an ICS and a LABA combined in a single inhaler (ICS/LABA), inhaled short-acting $\beta 2$-agonists (SABAs), inhaled long-acting muscarinic antagonists (LAMAs), short-acting muscarinic antagonists (SAMAs), a SAMA and a SABA combined in a single inhaler (SAMA/ SABA), oral leukotriene antagonists, xanthine derivatives, mast cell stabilizers, and systemic corticosteroids (CSs). Within the COPD cohort, patients were divided into ACO and COPD alone groups, based on the following asthma criteria: (1) diagnosis with asthma at least twice, as a principal or secondary diagnosis (ICD-10 codes J45 and J46); (2) at least one prescription for $\geq 1$ of the following asthma medications: ICSs, LABAs, ICS/LABA, SABAs, oral leukotriene antagonists, xanthine derivatives, mast cell stabilizers, and systemic CSs. Patients who met both criteria for COPD and asthma were defined as ACO.

Patients were excluded from the analysis of the incidence of depression and anxiety if they were diagnosed with depression or anxiety within 1 year of the index date. A study flow chart is presented in Fig. 1.

\section{Follow-up to depression and anxiety}

We defined the outcome as time to first diagnosis with depression (ICD-10: F32 and F33) or anxiety (ICD-10: F40-F42) as the primary or secondary diagnosis after the index date. The index date was defined as the first date that both definitions of COPD and asthma were met. For example, if a patient with asthma met the definition of COPD later, the patient was considered eligible for inclusion in the ACO cohort from the day the patient met the definition of COPD. Patients with COPD alone were defined as those who met the definition of COPD but did not meet the definition of asthma, and the index date was defined as the first date when the patient met the definition of COPD. Follow-up was considered to have started on the index date and to have ended on the date of first diagnosis with depression or anxiety, the date the patient died, or 31 December, 2013 (Fig. 2).

\section{Potential confounders}

Age, sex, comorbidities, and concurrent medications are all possible confounders of the association between ACO or COPD and depression or anxiety. We calculated the Charlson comorbidity index to estimate the severity of disease according to previous diagnoses within one year before the index date. We selected as confounders any comorbidities that may influence the risk of depression or anxiety, which included hypertension, diabetes, hyperlipidaemia, ischaemic heart disease, sleep disorders, alcohol-related illnesses, epilepsy, cancer, arthritis, Parkinson's disease, dementia, obesity, cerebrovascular disease, and atherosclerosis [22]. Concurrent medications were identified based on the prescriptions within 6 months before the date of each outcome to adjust the effect of using the medications just before the occurrence of the outcomes; in analysing the incidence of depression, we used the prescription information within 6 months before the date of depression, and in the same way, we used the prescription information within 6 months before the date of anxiety in analysing the incidence of anxiety. Benzodiazepines, digitalis, and calcium antagonists - including diltiazem, nifedipine, and verapamil - were selected as confounders because they were the frequently reported medications that might increase the risk of depression or anxiety [23]. In addition, patients' history of exacerbation and healthcare utilization were also included as potential confounders. Within the $\mathrm{ACO}$ and COPD cohort, patients were classified by the frequency of exacerbations they experienced within one year before the index date: frequent $(\geq 2)$, infrequent (1), and not exacerbated (0). Indicators for exacerbation were identified based on ICD codes (primary diagnosis) related to COPD (or asthma in ACO) present in combination with one of the following: (1) hospitalization, (2) emergency department visit, or (3) outpatient visit with either an oral corticosteroid or antibiotic prescription within 5 days of the visit $[24,25]$. To take into account for healthcare use other than for exacerbation, we included non-exacerbation related healthcare use in the preceding year of the index date as a potential confounder, which was further classified by the type of healthcare use: (1) hospitalizations, (2) emergency department visit, or (3) outpatient visit.

\section{Statistical analysis}

We estimated the propensity scores for being defined as having ACO regardless of the outcomes by using multiple logistic regression analysis with the following variables: age category, sex, Charlson comorbidity index, history of comorbidities, exacerbations, and healthcare use in previous year, insurance type and index year. We assessed the model discrimination using the $\mathrm{C}$ statistic. Matching was performed using a Greedy $5 \rightarrow 1$ digit matching macro with the estimated propensity score [26]. We used a standardized difference to compare baseline characteristics between patients with $\mathrm{ACO}$ and patients with COPD alone. We defined significant difference as an absolute value greater than 0.1 [27].

We calculated the incidence rate per 1000 person-years by dividing the number of diagnoses of depression or anxiety by the total number of person-years at risk and multiplying the results by 1000 . We also calculated the associated 95\% confidence interval (CI). For construction 
National Sample Cohort data

from the National Health Insurance Service

$\mathrm{n}=1,113,656$

Patients $\geq 40$ years of age who were diagnosed with COPD

(ICD-10 codes: J42-J44) at least twice

and prescribed COPD medication at least once

between 1 Jan, 2003 and $31 \mathrm{Dec}, 2011$

$\mathrm{n}=28,116$

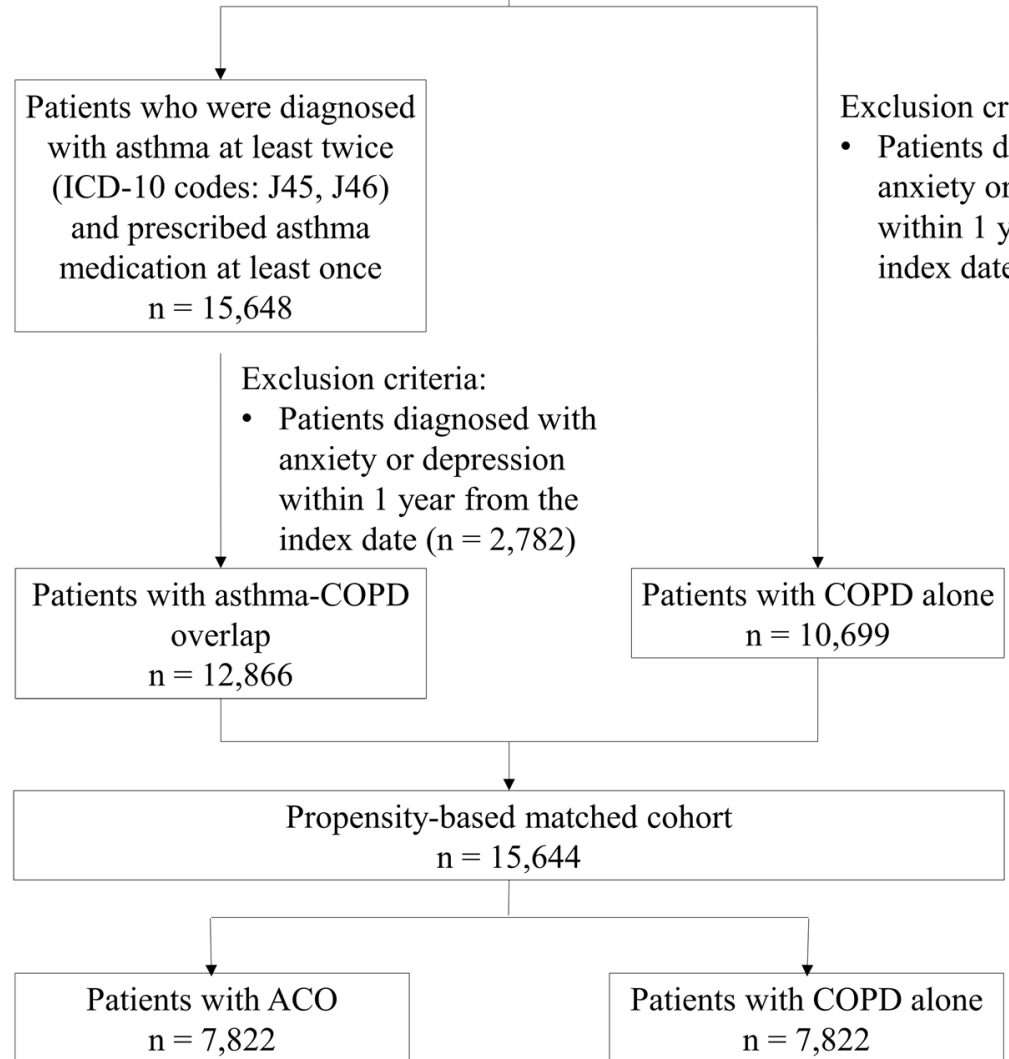

Fig. 1 The selection of study subjects. COPD, chronic obstructive pulmonary disease; ICD-10, International Classification of Diseases; ACO, asthma-COPD overlap

of the multivariable model, we included the use of concurrent medications prescribed within 6 months before the date of the outcome as the adjusting variable. We used the Cox regression models to estimate the adjusted hazard ratios (aHRs) and their 95\% CIs for depression and anxiety after adjusting for the concurrent medications in the propensity-based matched cohort.

We also conducted a subgroup analysis for the incidence of depression and anxiety according to age group, sex, comorbidities, and concurrent medications. We did subgroup analysis with interaction terms to see whether the association between ACO and incident depression or anxiety differed significantly by comorbidities and concurrent medications. All tests were 2-sided, with a significance level of 0.05. All data transformations and statistical analyses were conducted using SAS version 9.4 for Windows (SAS Institute, Cary, NC, USA).

\section{Results}

From the NHIS-NSC database, 28,116 COPD patients aged over 40 were diagnosed with COPD more than twice between January 2003 and December 2011. Of these, we identified 15,648 patients with ACO and 12,468 patients with COPD alone. After excluding patients who were diagnosed with anxiety or depression within 1 year before the index date, 12,866 patients were included in the initial cohort of ACO and 10,699 patients were included in the initial cohort of COPD alone. 


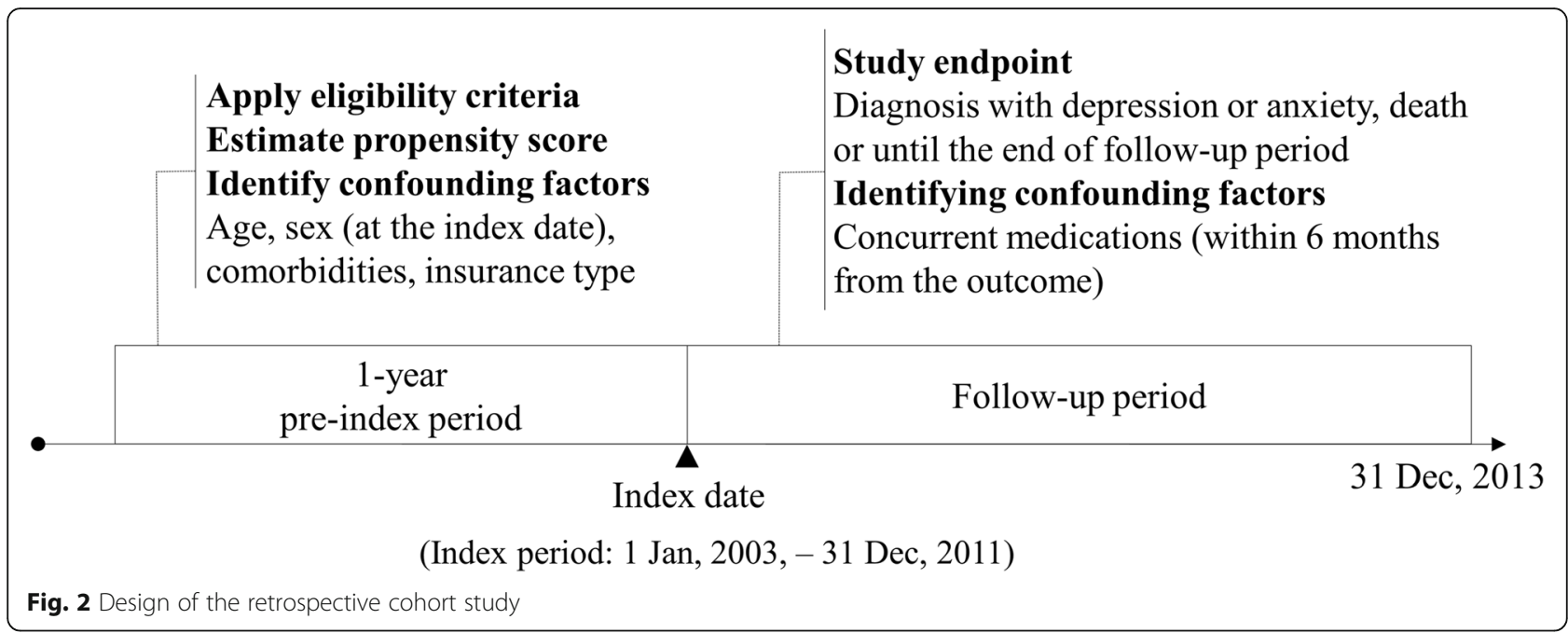

After propensity score estimation and matching in a one to one ratio, the cohort used in the analysis of depression and anxiety in patients with $\mathrm{ACO}$ versus patients with COPD alone included 15,644 patients (Fig. 1). Table 1 shows that clinical characteristics (age, sex, Charlson comorbidity index, history of comorbidities, exacerbations and healthcare use in previous year, insurance type, and index year) were not significantly different between patients with $\mathrm{ACO}$ and patients with COPD alone.

As shown in Table 2, the incidence rate of depression was 44.0 per 1000 person-years in patients with $\mathrm{ACO}$ and 38.2 per 1000 person-years in patients with COPD alone. The crude HR of depression among patients with ACO was 1.15 (95\% CI, 1.08-1.23). After adjustment for the medications prescribed within 6 months before the date of the outcome, the adjusted HR was 1.10 (95\% CI, $1.03-1.18 ; P$ value $=0.0039$ ) An increased risk of depression was observed among patients aged 40-64 years with an adjusted HR of 1.21 (95\% CI, 1.10-1.34; $\mathrm{P}$ value $=0.0001)$, whereas the difference in risk among patients $\geq 65$ years was not significant between patients with $\mathrm{ACO}$ and patients with COPD alone. In women, the risk of depression was higher in patients with ACO (aHR, 1.18; 95\% CI, $1.07-1.29 ; \quad P$ value $=0.0005$ ); however, in men, the difference in risk between ACO patients and patients with COPD alone was not significant (aHR, 1.03; 95\% CI, 0.93-1.13; $P=0.5718$ ).

The incidence rate of anxiety was 79.5 per 1000 person-years in patients with ACO and 72.9 per 1000 person-years in patients with COPD alone. The crude HR of anxiety in patients with ACO was 1.09 (95\% CI, 1.04-1.15). After adjustment for the medication prescribed within 6 months before the date of outcome, the adjusted HR was 1.06 (95\% CI, 1.011.12 ; $P$ value $=0.0272$ ). In patients aged $40-64$ years, the risk of anxiety in patients with ACO was significant when compared with that in patients with COPD alone (aHR, 1.08; 95\% CI, 1.00-1.17; P value $=0.0392$ ), and ACO patients $\geq 65$ years also did not have a significantly higher risk of anxiety (aHR 1.04; 95\% CI, 0.97-1.11; $\mathrm{P}$ value $=0.3314)$. The risk of anxiety was not significant in men (aHR, 1.06; 95\% CI, 0.98-1.14; $\mathrm{P}$ value $=0.1349)$, nor in women $(\mathrm{aHR}$, 1.06 ; 95\% CI, 0.99-1.14; $P$ value $=0.0891$ )

Table 3 shows the risk of depression in subgroups according to history of comorbidities in the previous year and use of concurrent medications within 6 months before the date of outcome. We found no difference in risk associated with the comorbidities and concurrent medications, except alcohol-related illness and use of corticosteroids. The hazard ratio was higher among patients with pre-existing alcohol-related illness than those without the illness (aHR, 2.12; 95\% CI, 1.44-3.12 versus aHR, 1.08; 95\% CI, 1.01-1.16; $\mathrm{P}$ value for interaction $=0.0008$ ). Table 4 shows the risk of anxiety according to history of comorbidities in previous year and use of concurrent medications within 6 months before the date of outcome. Any comorbidities and concurrent medications did not increase the risk of anxiety.

Table 5 shows the association between the use of concurrent medications prescribed within 6 months before the date of depression or anxiety and the incidence of depression or anxiety. Among the frequently reported four types of medication that might increase the risk of depression or anxiety, calcium channel blocker, corticosteroid, and benzodiazepines were significantly associated with a higher incidence of depression or anxiety. Digitalis did not show a significant association with the incidence of depression or anxiety. 
Table 1 Comparison of clinical characteristics between patients with ACO versus patients with COPD alone

\begin{tabular}{|c|c|c|c|c|}
\hline \multirow[t]{2}{*}{ Category } & \multicolumn{2}{|c|}{ No. of patients (\%) } & \multirow{2}{*}{$\begin{array}{l}P \\
\text { value }\end{array}$} & \multirow{2}{*}{$\begin{array}{l}\text { Standardized } \\
\text { difference }^{a}\end{array}$} \\
\hline & $\mathrm{ACO}(n=7822)$ & COPD alone $(n=7822)$ & & \\
\hline \multicolumn{5}{|l|}{ Age group (years) } \\
\hline $40-64$ & $3700(47.3)$ & $3718(47.53)$ & \multirow[t]{2}{*}{0.7732} & \multirow[t]{2}{*}{0.00461} \\
\hline$\geq 65$ & $4122(52.7)$ & $4104(52.47)$ & & \\
\hline \multicolumn{5}{|l|}{ Sex } \\
\hline Male & $4170(53.31)$ & $4176(53.39)$ & \multirow[t]{2}{*}{0.9234} & \multirow[t]{2}{*}{0.00154} \\
\hline Female & 3652(46.69) & $3646(46.61)$ & & \\
\hline \multicolumn{5}{|l|}{ Charlson comorbidity index } \\
\hline 0 & 1436(18.36) & $1537(19.65)$ & \multirow[t]{5}{*}{0.3501} & \multirow[t]{5}{*}{0.03368} \\
\hline 1 & 2645(33.81) & 2603(33.28) & & \\
\hline 2 & $1649(21.08)$ & $1642(20.99)$ & & \\
\hline 3 & $877(11.21)$ & $855(10.93)$ & & \\
\hline$\geq 4$ & $1215(15.53)$ & $1185(15.15)$ & & \\
\hline \multicolumn{5}{|c|}{ History of comorbidities in previous year } \\
\hline Hypertension & $2741(35.04)$ & $2671(34.15)$ & 0.2394 & 0.01881 \\
\hline Diabetes & 1558(19.92) & $1519(19.42)$ & 0.4328 & 0.01254 \\
\hline Hyperlipidaemia & 1319(16.86) & 1313(16.79) & 0.898 & 0.00205 \\
\hline Ischaemic heart disease & 633(8.09) & $595(7.61)$ & 0.2586 & 0.01806 \\
\hline Sleep disorder & $600(7.67)$ & $559(7.15)$ & 0.2107 & 0.02001 \\
\hline Alcohol-related illness & 238(3.04) & $225(2.88)$ & 0.5397 & 0.00981 \\
\hline Epilepsy & $67(0.86)$ & $62(0.79)$ & 0.6585 & 0.00707 \\
\hline Cancer & $895(11.44)$ & $874(11.17)$ & 0.596 & 0.00848 \\
\hline Arthritis & 1552(19.84) & $1537(19.65)$ & 0.7632 & 0.00482 \\
\hline Parkinson's disease & $41(0.52)$ & $42(0.54)$ & 0.9124 & 0.00176 \\
\hline Dementia & $72(0.92)$ & $86(1.1)$ & 0.2629 & 0.0179 \\
\hline Obesity & $3(0.04)$ & $7(0.09)$ & 0.2058 & 0.02023 \\
\hline Cerebrovascular disease & $621(7.94)$ & $606(7.75)$ & 0.6555 & 0.00713 \\
\hline Atherosclerosis & $168(2.15)$ & $160(2.05)$ & 0.6553 & 0.00714 \\
\hline \multicolumn{5}{|c|}{ History of exacerbation in previous year } \\
\hline 0 & $62(0.79)$ & $70(0.89)$ & 0.4844 & 0.01118 \\
\hline 1 & 1636(20.92) & $1688(21.58)$ & 0.3095 & 0.01625 \\
\hline$\geq 2$ & 6124(78.29) & $6064(77.52)$ & 0.2476 & 0.01849 \\
\hline \multicolumn{5}{|c|}{ Healthcare utilization in previous year } \\
\hline Hospitalization & 1327(16.96) & $1347(17.22)$ & 0.671 & 0.00679 \\
\hline ED visit & $723(9.24)$ & $701(8.96)$ & 0.5409 & 0.00978 \\
\hline Outpatient visit & $7321(93.59)$ & $7302(93.35)$ & 0.5385 & 0.00983 \\
\hline \multicolumn{5}{|l|}{ Insurance type } \\
\hline Health insurance & 7529(96.25) & 7504(95.93) & 0.3022 & 0.0165 \\
\hline Medical-aid beneficiary & 293(3.75) & $318(4.07)$ & & \\
\hline \multicolumn{5}{|l|}{ Index year } \\
\hline 2003 & 1483(18.96) & $1435(18.35)$ & 0.3245 & 0.01575 \\
\hline 2004 & $1107(14.15)$ & 1032(13.19) & 0.0809 & 0.02791 \\
\hline 2005 & $910(11.63)$ & $943(12.06)$ & 0.4142 & 0.01306 \\
\hline 2006 & $847(10.83)$ & $916(11.71)$ & 0.0811 & 0.0279 \\
\hline
\end{tabular}


Table 1 Comparison of clinical characteristics between patients with ACO versus patients with COPD alone (Continued)

\begin{tabular}{lllll}
\hline Category & No. of patients (\%) & & $\begin{array}{c}P \\
\text { value }\end{array}$ & $\begin{array}{c}\text { Standardized } \\
\text { difference }\end{array}$ \\
\cline { 2 - 5 } & ACO $(n=7822)$ & COPD alone $(n=7822)$ & 0.1761 & 0.02163 \\
2007 & $765(9.78)$ & $816(10.43)$ & 0.3006 & 0.01655 \\
2008 & $770(9.84)$ & $809(10.34)$ & 0.1404 & 0.02358 \\
2009 & $768(9.82)$ & $714(9.13)$ & 0.5754 & 0.00896 \\
2010 & $565(7.22)$ & $547(6.99)$ & 0.9286 & 0.00143 \\
2011 & $607(7.76)$ & $610(7.8)$ & & \\
\hline
\end{tabular}

ACO asthma-COPD overlap, COPD chronic obstructive pulmonary disease, ED emergency department

${ }^{a} \mathrm{~A}$ standardized mean difference of greater than 0.1 represents significant difference between the two cohorts

\section{Discussion}

\section{Principal findings}

In this population-based cohort study, we evaluated the association between ACO and the risk of depression and anxiety. Compared to patients with COPD alone, patients with ACO had a 1.10-fold increased risk of depression and 1.06-fold increased risk of anxiety. The risk of depression was higher in patients aged 40-64 years old and in women, but was not affected by presence of comorbidities within 1 year from the index date nor the use of concurrent medications within 6 months before the date of outcome, except the presence of alcohol-related illness. The risk of anxiety was higher in patients aged 40-64 years old, but was not affected by presence of comorbidities nor the use of concurrent medications.
Our finding suggests that there is significant risk of depression and anxiety in patients with ACO compared with patients with COPD alone, irrespective of presence of comorbidities and use of concurrent medications.

\section{Comparison with other studies}

Our findings are consistent with a previous cohort study in that women and patients $\geq 65$ years of age were found to have a higher rate of depression than men and patients $<65$ years of age [15]. The higher incidence of depression in our Korean study population compared to that of in the Taiwanese population can be explained by the higher prevalence of mental disorders in Korea than in Taiwan $[28,29]$. In addition, our results are also similar to those from a previous study which showed the risk

Table 2 Risk of depression and anxiety in patients with ACO versus patients with COPD alone

\begin{tabular}{|c|c|c|c|c|c|c|c|c|c|}
\hline \multirow[t]{2}{*}{ Category } & \multicolumn{3}{|c|}{$\mathrm{ACO}(n=7822)$} & \multicolumn{3}{|c|}{ COPD alone $(n=7822)$} & \multirow{2}{*}{$\begin{array}{l}\text { Crude HR } \\
(95 \% \mathrm{Cl})\end{array}$} & \multirow{2}{*}{$\begin{array}{l}\text { Adjusted }{ }^{a} \mathrm{HR} \\
(95 \% \mathrm{Cl})\end{array}$} & \multirow{2}{*}{$\begin{array}{l}P \text { value } \\
\text { for } \\
\text { adjusted } \\
\text { HR }\end{array}$} \\
\hline & Events & PY & Rate & Events & PY & Rate & & & \\
\hline \multicolumn{10}{|l|}{ Depression } \\
\hline Overall & 1908 & 43,380 & 44.0 & 1654 & 43,342 & 38.2 & $1.15(1.08-1.23)$ & $1.10(1.03-1.18)$ & 0.0039 \\
\hline \multicolumn{10}{|l|}{ Age groups (years) } \\
\hline $40-64(n=7418)$ & 886 & 22,402 & 39.5 & 727 & 22,817 & 31.9 & $1.24(1.13-1.37)$ & $1.21(1.10-1.34)$ & 0.0001 \\
\hline$\geq 65(n=8226)$ & 1022 & 20,978 & 48.7 & 927 & 20,525 & 45.2 & $1.08(0.99-1.18)$ & $1.01(0.93-1.11)$ & 0.7537 \\
\hline \multicolumn{10}{|l|}{ Sex } \\
\hline Male $(n=8346)$ & 879 & 22,891 & 38.4 & 792 & 22,448 & 35.3 & $1.09(0.99-1.20)$ & $1.03(0.93-1.13)$ & 0.5718 \\
\hline Female $(n=7298)$ & 1029 & 20,490 & 50.2 & 862 & 20,894 & 41.3 & $1.22(1.11-1.33)$ & $1.18(1.07-1.29)$ & 0.0005 \\
\hline \multicolumn{10}{|l|}{ Anxiety } \\
\hline Overall & 3017 & 37,927 & 79.5 & 2780 & 38,155 & 72.9 & $1.09(1.04-1.15)$ & $1.06(1.01-1.12)$ & 0.0272 \\
\hline \multicolumn{10}{|l|}{ Age groups (years) } \\
\hline $40-64(n=7418)$ & 1416 & 19,663 & 72.0 & 1318 & 20,155 & 65.4 & $1.10(1.02-1.19)$ & $1.08(1.00-1.17)$ & 0.0392 \\
\hline$\geq 65(n=8226)$ & 1601 & 18,263 & 87.7 & 1462 & 18,000 & 81.2 & 1.08(1.00-1.16) & $1.04(0.97-1.11)$ & 0.3314 \\
\hline \multicolumn{10}{|l|}{ Sex } \\
\hline Male $(n=8346)$ & 1394 & 20,536 & 67.9 & 1272 & 20,462 & 62.2 & $1.09(1.01-1.18)$ & $1.06(0.98-1.14)$ & 0.1349 \\
\hline Female $(n=7298)$ & 1623 & 17,391 & 93.3 & 1508 & 17,693 & 85.2 & $1.09(1.02-1.17)$ & $1.06(0.99-1.14)$ & 0.0891 \\
\hline
\end{tabular}

Bold results represent statistically significant

ACO asthma-COPD overlap, COPD chronic obstructive pulmonary disease, $P Y$ person-year; Rate, incidence rate (per 1000 person-years); HR, hazard ratio ${ }^{a}$ Adjusted for medications - including calcium antagonists (diltiazem, nifedipine, verapamil), corticosteroids, digitalis, and benzodiazepines - prescribed within 6 months before the date of outcome 
Table 3 Subgroup analyses of risk of depression in patients with ACO versus patients with COPD alone

\begin{tabular}{|c|c|c|c|c|c|c|c|c|}
\hline \multirow[t]{2}{*}{ Category } & \multicolumn{3}{|c|}{$\operatorname{ACO}(n=7822)$} & \multicolumn{3}{|c|}{ COPD alone $(n=7822)$} & \multirow{2}{*}{$\begin{array}{l}\text { Adjusted }{ }^{a} \text { HR } \\
(95 \% \mathrm{Cl})\end{array}$} & \multirow{2}{*}{$\begin{array}{l}P \text { value for } \\
\text { interaction }\end{array}$} \\
\hline & Events & PY & Rate & Events & PY & Rate & & \\
\hline \multicolumn{9}{|c|}{ History of comorbidities in previous year } \\
\hline \multicolumn{9}{|l|}{ Hypertension } \\
\hline Yes $(n=5412)$ & 716 & 14,214 & 50.4 & 621 & 13,641 & 45.5 & 1.05(0.94-1.17) & \multirow[t]{2}{*}{0.2998} \\
\hline No $(n=10,232)$ & 1192 & 29,166 & 40.9 & 1033 & 29,701 & 34.8 & $1.13(1.04-1.23)$ & \\
\hline \multicolumn{9}{|l|}{ Diabetes } \\
\hline Yes $(n=3077)$ & 456 & 7961 & 57.3 & 367 & 7642 & 48.0 & $1.10(0.96-1.27)$ & \multirow[t]{2}{*}{0.9458} \\
\hline No $(n=12,567)$ & 1452 & 35,419 & 41.0 & 1287 & 35,700 & 36.1 & $1.10(1.02-1.18)$ & \\
\hline \multicolumn{9}{|l|}{ Hyperlipidemia } \\
\hline Yes $(n=2632)$ & 383 & 6425 & 59.6 & 337 & 6538 & 51.5 & 1.13(0.98-1.31) & \multirow[t]{2}{*}{0.6766} \\
\hline No $(n=13,012)$ & 1525 & 36,955 & 41.3 & 1317 & 36,805 & 35.8 & $1.10(1.02-1.18)$ & \\
\hline \multicolumn{9}{|c|}{ Ischaemic heart disease } \\
\hline Yes $(n=1228)$ & 181 & 3189 & 56.8 & 142 & 2812 & 50.5 & 1.09(0.87-1.36) & \multirow[t]{2}{*}{0.8601} \\
\hline No $(n=14,416)$ & 1727 & 40,191 & 43.0 & 1512 & 40,530 & 37.3 & $1.10(1.03-1.18)$ & \\
\hline \multicolumn{9}{|l|}{ Sleep disorder } \\
\hline Yes $(n=1159)$ & 228 & 2750 & 82.9 & 187 & 2546 & 73.4 & $1.10(0.91-1.34)$ & \multirow[t]{2}{*}{0.9332} \\
\hline No $(n=14,485)$ & 1680 & 40,630 & 41.3 & 1467 & 40,796 & 36.0 & $1.10(1.03-1.18)$ & \\
\hline \multicolumn{9}{|c|}{ Alcohol-related illness } \\
\hline Yes $(n=463)$ & 81 & 1207 & 67.1 & 39 & 1317 & 29.6 & $2.12(1.44-3.12)$ & \multirow[t]{2}{*}{0.0008} \\
\hline No $(n=15,181)$ & 1827 & 42,173 & 43.3 & 1615 & 42,026 & 38.4 & $1.08(1.01-1.16)$ & \\
\hline \multicolumn{9}{|l|}{ Epilepsy } \\
\hline Yes $(n=129)$ & 24 & 289 & 83.1 & 10 & 271 & 36.9 & $2.11(1.00-4.45)$ & \multirow[t]{2}{*}{0.0601} \\
\hline No $(n=15,515)$ & 1884 & 43,092 & 43.7 & 1644 & 43,071 & 38.2 & $1.10(1.03-1.17)$ & \\
\hline \multicolumn{9}{|l|}{ Cancer } \\
\hline Yes $(n=1769)$ & 271 & 4426 & 61.2 & 184 & 4243 & 43.4 & $1.31(1.09-1.58)$ & \multirow[t]{2}{*}{0.0562} \\
\hline No $(n=13,875)$ & 1637 & 38,954 & 42.0 & 1470 & 39,099 & 37.6 & $1.07(1.00-1.15)$ & \\
\hline Arthritis & & & & & & & & \\
\hline Yes $(n=3089)$ & 442 & 8333 & 53.0 & 413 & 8150 & 50.7 & $0.99(0.87-1.13)$ & 0.1019 \\
\hline No $(n=12,555)$ & 1466 & 35,048 & 41.8 & 1241 & 35,192 & 35.3 & $1.14(1.06-1.23)$ & \\
\hline Parkinson's disease & & & & & & & & \\
\hline Yes $(n=83)$ & 10 & 144 & 69.3 & 9 & 141 & 63.7 & $0.59(0.22-1.60)$ & 0.5441 \\
\hline No $(n=15,561)$ & 1898 & 43,236 & 43.9 & 1645 & 43,201 & 38.1 & $1.10(1.03-1.18)$ & \\
\hline Dementia & & & & & & & & \\
\hline Yes $(n=158)$ & 15 & 227 & 66.1 & 22 & 223 & 98.5 & $0.76(0.39-1.50)$ & 0.1681 \\
\hline No $(n=15,486)$ & 1893 & 43,153 & 43.9 & 1632 & 43,119 & 37.8 & $1.11(1.04-1.18)$ & \\
\hline Obesity & & & & & & & & \\
\hline Yes $(n=10)$ & 0 & 19 & 0.0 & 3 & 35 & 86.6 & 1.99(NA) & 0.8967 \\
\hline No $(n=15,634)$ & 1908 & 43,361 & 44.0 & 1651 & 43,308 & 38.1 & $1.10(1.03-1.18)$ & \\
\hline Cerebrovascular di & & & & & & & & \\
\hline Yes $(n=1227)$ & 172 & 2867 & 60.0 & 157 & 2642 & 59.4 & $0.96(0.77-1.20)$ & 0.1887 \\
\hline No $(n=14,417)$ & 1736 & 40,514 & 42.8 & 1497 & 40,700 & 36.8 & $1.12(1.04-1.20)$ & \\
\hline Atherosclerosis & & & & & & & & \\
\hline Yes $(n=328)$ & 47 & 751 & 62.6 & 33 & 722 & 45.7 & 1.23(0.79-1.94) & 0.7111 \\
\hline No $(n=15,316)$ & 1861 & 42,630 & 43.7 & 1621 & 42,620 & 38.0 & $1.10(1.03-1.18)$ & \\
\hline
\end{tabular}


Table 3 Subgroup analyses of risk of depression in patients with ACO versus patients with COPD alone (Continued)

\begin{tabular}{|c|c|c|c|c|c|c|c|c|}
\hline \multirow[t]{2}{*}{ Category } & \multicolumn{3}{|c|}{$\operatorname{ACO}(n=7822)$} & \multicolumn{3}{|c|}{ COPD alone $(n=7822)$} & \multirow{2}{*}{$\begin{array}{l}\text { Adjusted }^{a} \mathrm{HR} \\
(95 \% \mathrm{Cl})\end{array}$} & \multirow{2}{*}{$\begin{array}{l}P \text { value for } \\
\text { interaction }\end{array}$} \\
\hline & Events & PY & Rate & Events & PY & Rate & & \\
\hline \multicolumn{9}{|c|}{ Use of concurrent medications within 6 months before the date of outcomes } \\
\hline \multicolumn{9}{|l|}{ Calcium antagonists } \\
\hline Yes $(n=892)$ & 149 & 2150 & 69.3 & 109 & 1796 & 60.7 & $1.09(0.85-1.40)$ & 0.7505 \\
\hline No $(n=14,752)$ & 1759 & 41,230 & 42.7 & 1545 & 41,546 & 37.2 & $1.10(1.03-1.18)$ & \\
\hline \multicolumn{9}{|l|}{ Corticosteroids } \\
\hline Yes $(n=7658)$ & 1192 & 22,314 & 53.4 & 848 & 18,580 & 45.6 & $1.15(1.05-1.26)$ & 0.1887 \\
\hline No $(n=7986)$ & 716 & 21,066 & 34.0 & 806 & 24,762 & 32.6 & $1.05(0.95-1.16)$ & \\
\hline \multicolumn{9}{|l|}{ Digitalis } \\
\hline Yes $(n=509)$ & 67 & 1186 & 56.5 & 51 & 1007 & 50.7 & $1.11(0.77-1.61)$ & 0.9571 \\
\hline No $(n=15,135)$ & 1841 & 42,194 & 43.6 & 1603 & 42,335 & 37.9 & $1.10(1.03-1.18)$ & \\
\hline \multicolumn{9}{|l|}{ Benzodiazepines } \\
\hline Yes $(n=5425)$ & 1098 & 13,671 & 80.3 & 943 & 12,750 & 74.0 & $1.08(0.99-1.18)$ & 0.2176 \\
\hline No $(n=10,219)$ & 810 & 29,709 & 27.3 & 711 & 30,593 & 23.2 & $1.14(1.03-1.26)$ & \\
\hline
\end{tabular}

Bold results represent statistically significant $P$ value for interaction

ACO asthma-COPD overlap, COPD chronic obstructive pulmonary disease, PY person-year; Rate, incidence rate (per 1000 person-years); HR, hazard ratio

${ }^{a}$ Adjusted for medications - including calcium antagonists (diltiazem, nifedipine, verapamil), corticosteroids, digitalis, and benzodiazepines - prescribed within 6

months before the date of outcomes

of depression was greater in patient with alcohol-related illness [15].

To date, our study is the first longitudinal study that has examined the incidence of anxiety disorders in patients with ACO. Our results with respect to the incidence of anxiety showed a higher rate of anxiety in women than in men, which is consistent with previously reported patterns of the prevalence of anxiety disorders in Korea [30]. In addition, a retrospective cohort study has reported that anxiety is more prevalent in patients with ACO than in those with COPD alone, with an odds ratio of 1.18 (95\% CI, 1.10-1.27) [19]. Our results showed that the risk of anxiety is increased in patients with ACO compared with COPD alone. However, when we compared the risk of anxiety in ACO versus COPD patients in association with different treatments, the use of corticosteroid did not significantly increase the risk of anxiety. That is, the risk of anxiety in the patients with ACO, compared with patients with COPD alone, did not change with the use of corticosteroid.

Several studies have shown that patients with ACO have more severe respiratory symptoms, more frequent exacerbations and hospitalizations than those with COPD alone [7, 31]. In addition, COPD is treated mainly with bronchodilators, whereas ICS is recommended for the treatment of ACO patient with features of asthma [7]. Therefore, patients with ACO are not only exposed to frequent use of systemic corticosteroids due to exacerbations, but they are also more treated with regular ICS, compared to those with COPD alone. Corticosteroids exposure leading to mood disorder can be explained by the fact that chronic corticosteroid use has been associated with alterations in central and peripheral serotonin levels [32, 33]. Further studies are needed to understand the mechanism behind the higher risk of mood disorder in patients with ACO compared to those with COPD.

Association between alcohol-related illness and higher incidence of depression in patients with ACO can be explained by a research that showed acetaldehyde causing bronchoconstriction indirectly via histamine-mediated process in asthma patients [34]. Through the process of ethanol metabolism, mainly by aldehyde dehydrogenase (ALDH), ethanol is oxidized to acetaldehyde, which is further oxidized to acetate. However, many East Asian people were reported to be deficient in ALDH2, one of the ALDH isozymes [35]. When they ingest ethanol, their blood acetaldehyde and histamine levels increase significantly due to insufficient metabolic activity, and the increased histamine may result in bronchoconstriction [34, 36]. Therefore, alcohol-related illnesses in ACO patients may cause more frequent exacerbations and lead to increased risk of depression. However, why the risk of anxiety was not affected by the presence of alcohol-related illness remains unexplained, and further studies are needed.

Previous studies have shown that mood disorders cause frequent exacerbations in asthma and COPD patients [37, 38]; this can be caused by the low compliance with medication [39]. Anxiety and depression have also been associated with the activation of the hypothalamic-pituitary-adrenal axis [40], which could increase the systemic inflammatory 
Table 4 Subgroup analyses of risk of anxiety in patients with ACO versus patients with COPD alone

\begin{tabular}{|c|c|c|c|c|c|c|c|c|}
\hline \multirow[t]{2}{*}{ Category } & \multicolumn{3}{|c|}{$\mathrm{ACO}(n=7822)$} & \multicolumn{3}{|c|}{ COPD alone $(n=7822)$} & \multirow{2}{*}{$\begin{array}{l}\text { Adjusted }{ }^{a} H R \\
(95 \% \text { Cl) }\end{array}$} & \multirow{2}{*}{$\begin{array}{l}P \text { value for } \\
\text { interaction }\end{array}$} \\
\hline & Events & PY & Rate & Events & PY & Rate & & \\
\hline \multicolumn{9}{|c|}{ History of comorbidities in previous year } \\
\hline \multicolumn{9}{|l|}{ Hypertension } \\
\hline Yes $(n=5412)$ & 1115 & 12,372 & 90.1 & 993 & 11,984 & 82.9 & $1.06(0.97-1.15)$ & \multirow[t]{2}{*}{0.977} \\
\hline No $(n=10,232)$ & 1902 & 25,555 & 74.4 & 1787 & 26,171 & 68.3 & $1.06(0.99-1.13)$ & \\
\hline \multicolumn{9}{|l|}{ Diabetes } \\
\hline Yes $(n=3077)$ & 654 & 6938 & 94.3 & 574 & 6758 & 84.9 & $1.07(0.96-1.20)$ & \multirow[t]{2}{*}{0.8967} \\
\hline No $(n=12,567)$ & 2363 & 30,989 & 76.3 & 2206 & 31,397 & 70.3 & $1.06(1.00-1.12)$ & \\
\hline \multicolumn{9}{|l|}{ Hyperlipidemia } \\
\hline Yes $(n=2632)$ & 582 & 5597 & 104.0 & 514 & 5797 & 88.7 & $1.12(1.00-1.27)$ & \multirow[t]{2}{*}{0.2248} \\
\hline No $(n=13,012)$ & 2435 & 32,330 & 75.3 & 2266 & 32,359 & 70.0 & $1.05(0.99-1.11)$ & \\
\hline \multicolumn{9}{|c|}{ Ischaemic heart disease } \\
\hline Yes $(n=1228)$ & 273 & 2819 & 96.8 & 202 & 2513 & 80.4 & $1.20(1.00-1.44)$ & \multirow[t]{2}{*}{0.155} \\
\hline No $(n=14,416)$ & 2744 & 35,108 & 78.2 & 2578 & 35,643 & 72.3 & $1.05(0.99-1.11)$ & \\
\hline \multicolumn{9}{|l|}{ Sleep disorder } \\
\hline Yes $(n=1159)$ & 314 & 2363 & 132.9 & 277 & 2095 & 132.2 & $1.02(0.86-1.20)$ & \multirow[t]{2}{*}{0.5789} \\
\hline No $(n=14,485)$ & 2703 & 35,564 & 76.0 & 2503 & 36,060 & 69.4 & $1.06(1.01-1.12)$ & \\
\hline \multicolumn{9}{|c|}{ Alcohol-related illness } \\
\hline Yes $(n=463)$ & 103 & 1156 & 89.1 & 82 & 1116 & 73.5 & $1.16(0.86-1.55)$ & \multirow[t]{2}{*}{0.6018} \\
\hline No $(n=15,181)$ & 2914 & 36,771 & 79.2 & 2698 & 37,039 & 72.8 & $1.06(1.00-1.12)$ & \\
\hline \multicolumn{9}{|l|}{ Epilepsy } \\
\hline Yes $(n=129)$ & 23 & 286 & 80.5 & 19 & 236 & 80.6 & $1.12(0.60-2.11)$ & \multirow[t]{2}{*}{0.9961} \\
\hline No $(n=15,515)$ & 2994 & 37,641 & 79.5 & 2761 & 37,920 & 72.8 & $1.06(1.01-1.12)$ & \\
\hline \multicolumn{9}{|l|}{ Cancer } \\
\hline Yes $(n=1769)$ & 351 & 3962 & 88.6 & 316 & 3710 & 85.2 & $0.98(0.84-1.15)$ & \multirow[t]{2}{*}{0.2878} \\
\hline No $(n=13,875)$ & 2666 & 33,964 & 78.5 & 2464 & 34,445 & 71.5 & $1.07(1.01-1.13)$ & \\
\hline Arthritis & & & & & & & & \\
\hline Yes $(n=3089)$ & 718 & 6980 & 102.9 & 690 & 6866 & 100.5 & $1.00(0.90-1.10)$ & 0.1798 \\
\hline No $(n=12,555)$ & 2299 & 30,947 & 74.3 & 2090 & 31,290 & 66.8 & $1.08(1.02-1.15)$ & \\
\hline Parkinson's disease & & & & & & & & \\
\hline Yes $(n=83)$ & 16 & 118 & 135.0 & 16 & 125 & 128.0 & $0.73(0.34-1.60)$ & 0.5775 \\
\hline No $(n=15,561)$ & 3001 & 37,808 & 79.4 & 2764 & 38,030 & 72.7 & $1.06(1.01-1.12)$ & \\
\hline Dementia & & & & & & & & \\
\hline Yes $(n=158)$ & 20 & 196 & 102.2 & 24 & 226 & 106.4 & $1.19(0.64-2.22)$ & 0.7515 \\
\hline No $(n=15,486)$ & 2997 & 37,731 & 79.4 & 2756 & 37,930 & 72.7 & $1.06(1.01-1.12)$ & \\
\hline Obesity & & & & & & & & \\
\hline Yes $(n=10)$ & 0 & 19 & 0.0 & 4 & 24 & 167.4 & $1.12(\mathrm{NA})$ & 0.8607 \\
\hline No $(n=15,634)$ & 3017 & 37,907 & 79.6 & 2776 & 38,131 & 72.8 & $1.06(1.01-1.12)$ & \\
\hline Cerebrovascular di & & & & & & & & \\
\hline Yes $(n=1227)$ & 257 & 2435 & 105.5 & 220 & 2382 & 92.3 & $1.11(0.92-1.33)$ & 0.4783 \\
\hline No $(n=14,417)$ & 2760 & 35,491 & 77.8 & 2560 & 35,773 & 71.6 & $1.06(1.00-1.11)$ & \\
\hline Atherosclerosis & & & & & & & & \\
\hline Yes $(n=328)$ & 70 & 701 & 99.9 & 58 & 633 & 91.6 & $0.98(0.69-1.41)$ & 0.5821 \\
\hline No $(n=15,316)$ & 2947 & 37,226 & 79.2 & 2722 & 37,522 & 72.5 & $1.06(1.01-1.12)$ & \\
\hline
\end{tabular}


Table 4 Subgroup analyses of risk of anxiety in patients with ACO versus patients with COPD alone (Continued)

\begin{tabular}{|c|c|c|c|c|c|c|c|c|}
\hline \multirow[t]{2}{*}{ Category } & \multicolumn{3}{|c|}{$\mathrm{ACO}(n=7822)$} & \multicolumn{3}{|c|}{ COPD alone $(n=7822)$} & \multirow{2}{*}{$\begin{array}{l}\text { Adjusted }{ }^{a} \mathrm{HR} \\
(95 \% \mathrm{Cl})\end{array}$} & \multirow{2}{*}{$\begin{array}{l}P \text { value for } \\
\text { interaction }\end{array}$} \\
\hline & Events & PY & Rate & Events & PY & Rate & & \\
\hline \multicolumn{9}{|c|}{ Use of concurrent medications within 6 months before the date of outcomes } \\
\hline \multicolumn{9}{|l|}{ Calcium antagonists } \\
\hline Yes $(n=859)$ & 199 & 1837 & 108.3 & 152 & 1494 & 101.8 & $1.02(0.82-1.26)$ & 0.3769 \\
\hline No $(n=14,785)$ & 2818 & 36,090 & 78.1 & 2628 & 36,662 & 71.7 & $1.06(1.01-1.12)$ & \\
\hline \multicolumn{9}{|l|}{ Corticosteroids } \\
\hline Yes $(n=7552)$ & 1767 & 18,848 & 93.7 & 1405 & 15,795 & 89.0 & $1.05(0.98-1.13)$ & 0.5356 \\
\hline No $(n=8092)$ & 1250 & 19,079 & 65.5 & 1375 & 22,360 & 61.5 & $1.08(1.00-1.17)$ & \\
\hline \multicolumn{9}{|l|}{ Digitalis } \\
\hline Yes $(n=511)$ & 92 & 1054 & 87.3 & 76 & 939 & 80.9 & $1.12(0.82-1.53)$ & 0.9439 \\
\hline No $(n=15,133)$ & 2925 & 36,873 & 79.3 & 2704 & 37,216 & 72.7 & $1.06(1.00-1.12)$ & \\
\hline \multicolumn{9}{|l|}{ Benzodiazepines } \\
\hline Yes $(n=5245)$ & 1510 & 10,570 & 142.9 & 1400 & 10,238 & 136.7 & $1.05(0.97-1.12)$ & 0.1742 \\
\hline No $(n=10,399)$ & 1507 & 27,357 & 55.1 & 1380 & 27,917 & 49.4 & $1.08(1.01-1.16)$ & \\
\hline
\end{tabular}

ACO asthma-COPD overlap, COPD chronic obstructive pulmonary disease, $P Y$ person-year; Rate, incidence rate (per 1000 person-years); HR, hazard ratio ${ }^{a}$ Adjusted for medications - including calcium antagonists (diltiazem, nifedipine, verapamil), corticosteroids, digitalis, and benzodiazepines - prescribed within 6 months before the date of outcome

responses and increase the risk of exacerbation. Acute exacerbation is a key indicator for assessing the degree of disease control and prognosis in patients with chronic respiratory diseases such as asthma, COPD, and ACO, because it increases mortality and lowers the quality of life $[41,42]$. When an impact of the $10 \%$ increase in the relative risk of the depression is estimated in each population of 10,000 patients with $\mathrm{ACO}$ and with COPD alone, 1000 patients with ACO will be at risk of developing depression, compared to those with COPD alone. A previous study showed that the rate of acute exacerbation in COPD patients with mood disorders increased by $56 \%$ compared to those without mood disorders [38]. This suggests that additional 1000 ACO patients are at higher risk of developing acute exacerbations, leading to poor clinical prognosis. Therefore, our results demonstrate a need for clinicians to carefully examine for signs of mood disorders in addition to respiratory symptoms.

\section{Strengths and limitations}

Our study has several strengths. First, to our knowledge, this is the first population-based cohort study comparing the risk of depression and anxiety between patients with ACO versus patients with COPD alone. The risk reported in previous studies was based on the comparison of patients with and without ACO, and the results showed there is a significant difference in the risk of depression between the two patient groups [15]. However, our study revealed that the increased risk is also observed in patients with ACO when they are compared with patients with COPD alone; thus, providing a basis for the importance of monitoring and paying greater attention to the signs or symptoms of depression and

Table 5 Associations between the use of concurrent medications and incidence of mood disorders

\begin{tabular}{|c|c|c|c|c|}
\hline \multirow{2}{*}{$\begin{array}{l}\text { Types of concurrent } \\
\text { medications }^{a}\end{array}$} & \multicolumn{2}{|l|}{ Depression } & \multicolumn{2}{|l|}{ Anxiety } \\
\hline & Adjusted $^{\mathrm{b}} \mathrm{HR}(95 \% \mathrm{Cl})$ & $P$ value & Adjusted $^{\mathrm{b}}$ HR (95\% Cl) & $P$ value \\
\hline $\mathrm{ACO}$ & $1.10(1.03-1.18)$ & 0.0039 & $1.06(1.01-1.12)$ & 0.0272 \\
\hline Calcium channel blockers & $1.30(1.15-1.48)$ & $<0.0001$ & $1.14(1.02-1.27)$ & 0.018 \\
\hline Corticosteroids & $1.20(1.12-1.28)$ & $<0.0001$ & $1.19(1.13-1.26)$ & $<0.0001$ \\
\hline Digitalis & $1.02(0.85-1.23)$ & 0.8139 & $0.88(0.75-1.02)$ & 0.098 \\
\hline Benzodiazepines & $2.92(2.73-3.13)$ & $<0.0001$ & $2.54(2.41-2.68)$ & $<0.0001$ \\
\hline
\end{tabular}

Bold results represent statistically significant

$A C O$ asthma-COPD overlap, COPD chronic obstructive pulmonary disease, $H R$ hazard ratio

${ }^{a}$ Medications were considered as concurrent if they were prescribed within 6 months before the date of depression or anxiety

${ }^{\mathrm{b}}$ Adjusted for medications - including calcium antagonists (diltiazem, nifedipine, verapamil), corticosteroids, digitalis, and benzodiazepines - prescribed within 6

months before the date of outcome 
anxiety in patients with ACO. Second, the use of a national sample cohort database was able to yield highly representative results and overcome the possible limitations (such as insufficient statistical power) arising from a small number of patients.

Certain potential limitations should be considered when interpreting our findings. The first limitation is the definition of $\mathrm{ACO}$ in our study, and because this is a very contentious area already, the ACO cohort in this study was based on a subset of the COPD cohort. There is no formal definition of ACO [7]; therefore, we defined ACO based on the clinical diagnoses and corresponding prescribed medications. Although the definition of ACO has varied widely, the prevalence of ACO in our study is similar to that in previous studies $[8,12]$, which is estimated to be 52 to $55 \%$ of patients with COPD in database studies and 1.6 to $4.5 \%$ in the general population. The prevalence of ACO in our study was $56 \%(15,648 /$ $28,116)$ in patients with COPD and $1.4 \%(15,648 /$ $1,113,656)$ in the general population. Secondly, the measurement of outcomes was based on claims data, which does not capture patients with depression or anxiety that are not recorded in claims data (e.g. mild cases). Although there is a potential for inaccuracies in coding and for incompleteness of records, previous studies have validated the ICD-10 code-based definitions for diabetes and acute myocardial infarction (AMI), which were compared with medical records reviews and demonstrated positive predictive values of 72.3 to $87.2 \%$ for diabetes and $>70 \%$ for AMI [43, 44]. Third, residual confounding may exist due to the observational nature of this study. Several variables that could have affected the outcomes were not fully captured in the database, including smoking status, family history of mental illness, disease duration or severity, education level, and income level.

\section{Conclusions}

The present study of a large population-based cohort study revealed that, compared with patients with COPD alone, patients with ACO have an increased risk of depression and anxiety.

\begin{abstract}
Abbreviations
ACO: Asthma-COPD overlap; COPD: Chronic obstructive pulmonary disease; CSs: corticosteroids; GINA: Global Initiative for Asthma; GOLD: Global Initiative for Chronic Obstructive Lung Disease; ICD-10: International Classification of Diseases, 10th revision; ICSs: inhaled corticosteroids; LABAs: long-acting $32-$ agonists; LAMAs: long-acting muscarinic antagonists; NHIS: National Health Insurance Service; NSC: National Sample Cohort data; SABAs: short-acting $\beta 2-$ agonists; SAMAs: short-acting muscarinic antagonists
\end{abstract}

\section{Acknowledgments}

Not applicable.

\section{Funding}

This research was supported by a grant from the Korea Health Technology R\&D Project through the Korea Health Industry Development Institute
(KHIDI), which was funded by the Ministry of Health \& Welfare, Republic of Korea (grant number: HC15C1335).

\section{Availability of data and materials}

The data that support the findings of this study are available from the National Health Insurance Sharing Service (https://nhiss.nhis.or.kr/bd/ab/ bdaba000eng.do) but restrictions apply to the availability of these data, which were used under permission for the current study only, and, therefore, they are not publicly available.

\section{Authors' contributions}

All authors participated in the design and conduction of the study, interpretation of the results, and review and approval of the manuscript.

\section{Ethics approval and consent to participate}

This study was approved by the institutional review board of Sungkyunkwan University in South Korea (SKKU-IRB-2018-03-024). All personal identifying information for the included patients was anonymous; therefore, informed consent for this study was waived by the institutional review board.

\section{Consent for publication}

Not applicable.

\section{Competing interests}

This study used the National Health Insurance Service data (NHIS-2018-2133). The authors declare no competing interest with the NHIS.

\section{Publisher's Note}

Springer Nature remains neutral with regard to jurisdictional claims in published maps and institutional affiliations.

Received: 9 July 2018 Accepted: 1 April 2019

Published online: 30 April 2019

References

1. Mannino DM, Higuchi K, Yu T-C, Zhou H, Li Y, Tian H, et al. Economic burden of COPD in the presence of comorbidities. Chest. 2015;148:138-50.

2. Yohannes AM, Alexopoulos GS. Depression and anxiety in patients with COPD. Eur Respir Rev. 2014;23:345-9.

3. Lee $Y C$, Lee $C T$, Lai YR, Chen VC, Stewart R. Association of asthma and anxiety: a nationwide population-based study in Taiwan. J Affect Disord. 2016;189:98-105.

4. Ciprandi G, Schiavetti I, Rindone E, Ricciardolo FL. The impact of anxiety and depression on outpatients with asthma. Ann Allergy Asthma Immunol. 2015;115:408-14.

5. Urrutia I, Aguirre U, Pascual S, Esteban C, Ballaz A, Arrizubieta I, et al. Impact of anxiety and depression on disease control and quality of life in asthma patients. J Asthma. 2012;49:201-8.

6. Papaiwannou A, Zarogoulidis P, Porpodis K, Spyratos D, Kioumis I, Pitsiou G, et al. Asthma-chronic obstructive pulmonary disease overlap syndrome (ACOS): current literature review. J Thorac Dis. 2014;6:S146-51.

7. Global Initiative for Asthma. Diagnosis and initial treatment of asthma, COPD and asthma-COPD overlap. 2017 https://ginasthma.org. Accessed 10 May 2018.

8. de Marco R, Pesce G, Marcon A, Accordini S, Antonicelli L, Bugiani M, et al. The coexistence of asthma and chronic obstructive pulmonary disease (COPD): prevalence and risk factors in young, middle-aged and elderly people from the general population. PLoS One. 2013;8:e62985.

9. Barrecheguren M, Esquinas C, Miravitlles M. The asthma-COPD overlap syndrome: a new entity? COPD Res Pract. 2015;1:8.

10. Bourdin A, Suehs CM, Marin G, Vachier I, Matzner-Lober E, Chanez P, et al. Asthma, COPD, and overlap in a national cohort: ACO on a gradient. J Allergy Clin Immunol. 2018;141:1516-8.

11. Hahn D. Distinct clinical phenotypes of airways disease: a primary-care clinician perspective. Eur Respir J. 2010;35:459.

12. Barrecheguren M, Esquinas C, Miravitlles M. The asthma-chronic obstructive pulmonary disease overlap syndrome (ACOS): opportunities and challenges. Curr Opin Pulm Med. 2015;21:74-9.

13. Hardin M, Silverman EK, Barr RG, Hansel NN, Schroeder JD, Make BJ, et al. The clinical features of the overlap between COPD and asthma. Respir Res. 2011;12:127. 
14. Miravitlles M, Soriano JB, Ancochea J, Munoz L, Duran-Tauleria E, Sanchez G, et al. Characterisation of the overlap COPD-asthma phenotype. Focus on physical activity and health status. Respir Med. 2013;107:1053-60.

15. Yeh JJ, Lin $\mathrm{CL}, \mathrm{Hsu} \mathrm{WH}, \mathrm{Kao} \mathrm{CH}$. The relationship of depression in asthma-chronic obstructive pulmonary disease overlap syndrome. PLoS One. 2017:12:e0188017.

16. Braman SS, Kaemmerlen JT, Davis SM. Asthma in the elderly. A comparison between patients with recently acquired and long-standing disease. Am Rev Respir Dis. 1991;143:336-40.

17. Borish L, Culp JA. Asthma: a syndrome composed of heterogeneous diseases. Ann Allergy Asthma Immunol. 2008;101:1-9.

18. Carr TF, Bleecker E. Asthma heterogeneity and severity. World Allergy Organ J. 2016;9:41.

19. van Boven JF, Roman-Rodriguez M, Palmer JF, Toledo-Pons N, Cosio BG, Soriano JB. Comorbidome, pattern, and impact of asthma-COPD overlap syndrome in real life. Chest. 2016;149:1011-20.

20. Goodwin RD, Scheckner B, Pena L, Feldman JM, Taha F, Lipsitz JD. A 10-year prospective study of respiratory disease and depression and anxiety in adulthood. Ann Allergy Asthma Immunol. 2014;113:565-70.

21. Lee J, Lee JS, Park SH, Shin SA, Kim K. Cohort profile: the National Health Insurance Service-National Sample Cohort (NHIS-NSC), South Korea. Int J Epidemiol. 2017;46:e15.

22. Vink D, Aartsen MJ, Schoevers RA. Risk factors for anxiety and depression in the elderly: a review. J Affect Disord. 2008;106:29-44.

23. Jain KK. Drug-induced neurological disorders., 3rd rev. and expanded ed. Cambridge: Hogrefe Publishing; 2012.

24. Siddiqi A, Sethi S. Optimizing antibiotic selection in treating COPD exacerbations. Int J COPD. 2008;3:31-44.

25. Lee TA, Wilke C, Joo M, Stroupe KT, Krishnan JA, Schumock GT, et al. Outcomes associated with tiotropium use in patients with chronic obstructive pulmonary disease. Arch Intern Med. 2009;169:1403-10.

26. Parsons LS. Reducing bias in a propensity score matched-pair sample using greedy matching techniques. Proceedings of the twenty-sixth annual SAS users group international conference. Long Beach: SAS Institute; 2001.

27. Austin PC. Using the standardised difference to compare the prevalence of a binary variable between two groups in observational research. Commun Stat Simul Comput. 2009;38:1228-34.

28. Liao SC, Chen WJ, Lee MB, Lung FW, Lai TJ, Liu CY, et al. Low prevalence of major depressive disorder in Taiwanese adults: possible explanations and implications. Psychol Med. 2012;42:1227-37.

29. Shin C, Kim Y, Park S, Yoon S, Ko YH, Kim YK, et al. Prevalence and associated factors of depression in general population of Korea: results from the Korea National Health and nutrition examination survey, 2014. J Korean Med Sci. 2017;32:1861-9.

30. Cho MJ, Seong SJ, Park JE, Chung IW, Lee YM, Bae A, et al. Prevalence and correlates of DSM-IV mental disorders in south Korean adults: the Korean epidemiologic catchment area study 2011. Psychiatry Investig. 2015;12:164-70.

31. Maselli DJ, Hanania NA. Asthma COPD overlap: impact of associated comorbidities. Pulm Pharmacol Ther. 2018;52:27-31.

32. Brown ES, Khan DA, Nejtek VA. The psychiatric side effects of corticosteroids. Ann Allergy Asthma Immunol. 1999;83:495-504.

33. Warrington TP, Bostwick JM. Psychiatric adverse effects of corticosteroids. Mayo Clin Proc. 2006;81:1361-7.

34. Myou S, Fujimura M, Nishi K, Ohka T, Matsuda T. Aerosolized acetaldehyde induces histamine-mediated bronchoconstriction in asthmatics. Am Rev Respir Dis. 1993;148:940-3.

35. Lee H, Kim SS, You KS, Park W, Yang JH, Kim M, et al. Asian flushing: genetic and sociocultural factors of alcoholism among east asians. Gastroenterol Nurs. 2014;37:327-36.

36. Kawano T, Matsuse H, Kondo Y, Machida I, Saeki S, Tomari S, et al. Acetaldehyde induces histamine release from human airway mast cells to cause bronchoconstriction. Int Arch Allergy Immunol. 2004;134:233-9.

37. Opolski M, Wilson I. Asthma and depression: a pragmatic review of the literature and recommendations for future research. Clin Pract Epidemiol Ment Health. 2005;1:18

38. Laurin C, Labrecque M, Dupuis G, Bacon SL, Cartier A, Lavoie KL. Chronic obstructive pulmonary disease patients with psychiatric disorders are at greater risk of exacerbations. Psychosom Med. 2009;71:667-74.

39. Haapakoski R, Ebmeier KP, Alenius H, Kivimaki M. Innate and adaptive immunity in the development of depression: an update on current knowledge and technological advances. Prog Neuro-Psychopharmacol Biol Psychiatry. 2016;66:63-72.

40. Bremmer MA, Beekman AT, Deeg DJ, Penninx BW, Dik MG, Hack CE, et al. Inflammatory markers in late-life depression: results from a populationbased study. J Affect Disord. 2008;106:249-55.

41. Soler-Cataluna JJ, Martinez-Garcia MA, Roman Sanchez P, Salcedo E, Navarro M, Ochando R. Severe acute exacerbations and mortality in patients with chronic obstructive pulmonary disease. Thorax. 2005;60:925-31.

42. Luskin AT, Chipps BE, Rasouliyan L, Miller DP, Haselkorn T, Dorenbaum A. Impact of asthma exacerbations and asthma triggers on asthma-related quality of life in patients with severe or difficult-to-treat asthma. J Allergy Clin Immunol Pract. 2014;2:544-52.

43. Kimm H, Yun JE, Lee SH, Jang Y, Jee SH. Validity of the diagnosis of acute myocardial infarction in korean national medical health insurance claims data: the Korean heart study (1). Korean Circ J. 2012;42:10-5.

44. Park le B, Kim J, Kim DJ, Chung CH, Oh JY, Park SW, et al. Diabetes epidemics in Korea: reappraise nationwide survey of diabetes "diabetes in Korea 2007". Diabetes Metab J. 2013:37:233-9.
Ready to submit your research? Choose BMC and benefit from:

- fast, convenient online submission

- thorough peer review by experienced researchers in your field

- rapid publication on acceptance

- support for research data, including large and complex data types

- gold Open Access which fosters wider collaboration and increased citations

- maximum visibility for your research: over $100 \mathrm{M}$ website views per year

At $\mathrm{BMC}$, research is always in progress.

Learn more biomedcentral.com/submissions 